\title{
Biochemical Effect of Low-Level Radiation on Human Beings Examined by Directly Attached Radioactive Mineral
}

\author{
Masao Takatori ${ }^{1, *}$ and Makoto Yagi ${ }^{2}$ \\ 113-6, Yagami, Saiwai-ku, Kawasaki, Kanagawa, 212-0056, Japan \\ ${ }^{2}$ 7-18-3, Sasashita, Kohnan-ku, Yokohama, Kanagawa, 234-0053, Japan
}

\begin{abstract}
Previously, we have reported the clinical significance of low-level radiation and also demonstrated the necessity to determine the threshold of radioactive levels in human beings. In the present study, apart from the direct exposure of alpha-ray with oral intake of radon ${ }^{222}$ dissolved water or inhaling radon ${ }^{222}$ gas, the experimental direct exposure to beta- and gamma-rays by wearing a cotton sack containing Samarskite with direct contact to skin for one month was conducted. The average of beta- and gamma-ray levels on the sack surface was approximately 400 $\mu S V / h o u r$. The biochemical laboratory tests involving immunological markers were assessed at the initial and end points. In this study, the partial but continual direct exposure of human body to beta- and gamma-rays for one month showed no harmful effects. There are no significant changes in any of the bio markers. Although this study is limited regarding the number of subjects, the procedure is quite simple; thus, the gathering data using this procedure by adjusting the types and levels of radioactivity would be helpful in finding out the accurate radioactive threshold in human beings.
\end{abstract}

Keywords: Samarskite, beta-ray, gamma-ray, radiation hormesis.

\section{INTRODUCTION}

The ionizing radiations can be classified into electromagnetic radiations that consist of X-rays and gamma rays; particle radiations including neutrons and charged alpha and beta particles.

Usually, low dose radiation refers to radiation with cumulative dose up to $100 \mathrm{mSv}$ although relevant doses may sometime be considered as low dose radiations [1].

Endogenously different enzymes are produced in our bodies that take part in the repair process of DNA damages working with high efficiency [2, 3]. It is considered that low level radiations cause increased production of these fundamental repair enzymes. Also, the process of cellular suicide biologically known as Apoptosis which is important to get the body rid of damaged cells is stimulated by low level radiations [4]. Different mutation is prohibited by immune system of the body to progressed in to cancer conditions. Low level radiations are said to stimulate this defensive immune system of the body. Furthermore, different scavenging processes in our body that work to expel the carcinogenic chemicals out of the cells are aroused by the low-level radiations [5]. Overall, biological effects of ionizing radiation can be classified into early or deterministic, which have a threshold, and delayed or stochastic, with no threshold.

*Address correspondence to this author at the Takatori Clinic, 13-6, Yagami, Saiwai-ku, Kawasaki, Kanagawa, 212-0056, Japan; Tel: +81-44-580-3132; Fax: +81-44-588-0118; E-mail: mcyy@mtc.biglobe.ne.jp
However, the biological influence of low-level radiation is still controversial and not fully established $[6,7]$. We have previously reported the clinical usefulness of low-level radiation as alternative treatment using experimental radioactive circumstances [8, 9]; the direct exposure of alpha-ray with oral intake of radon $\left(\mathrm{Rn}^{222}\right)$ dissolved water or inhaling radon $\left(\mathrm{Rn}^{222}\right)$ gas and the additional condition of beta- and gamma-rays with direct contact on artificial radioactive walls [8-10]. Through these studies with different radioactive conditions, we found out that the determination of the radioactive threshold levels in human beings is indispensable and could be the basis of investigation concerning bio-positivity of low-level radiation. As a fundamental analysis apart from the direct exposure of alpha-ray related to radon $\left(\mathrm{Rn}^{222}\right)$, in the current study we have used the simple model of exposure to beta- and gamma-rays by close contact with radioactive samarskite; wearing a cotton sack with samarskite inside for one month.

\section{MATERIALS AND METHODS}

As radioactive mineral, samarskite provided in private market was selected. The total of beta- and gamma-ray levels on the surface of each mineral was measured with Radiation alert Inspector (S.E. International INC.). Of these, a piece of samarskite with approximately over $400 \mu \mathrm{SV} /$ hour was selected. The Samarskite piece was crushed gently by hammer to particles approximately $10 \mathrm{~mm}$ in diameter, put into a cotton sack and worn like a necklace for one month. Because of the hindrances in obtaining informed consent from the participants for this study, the subject 
Table 1: Biolaboratory Markers

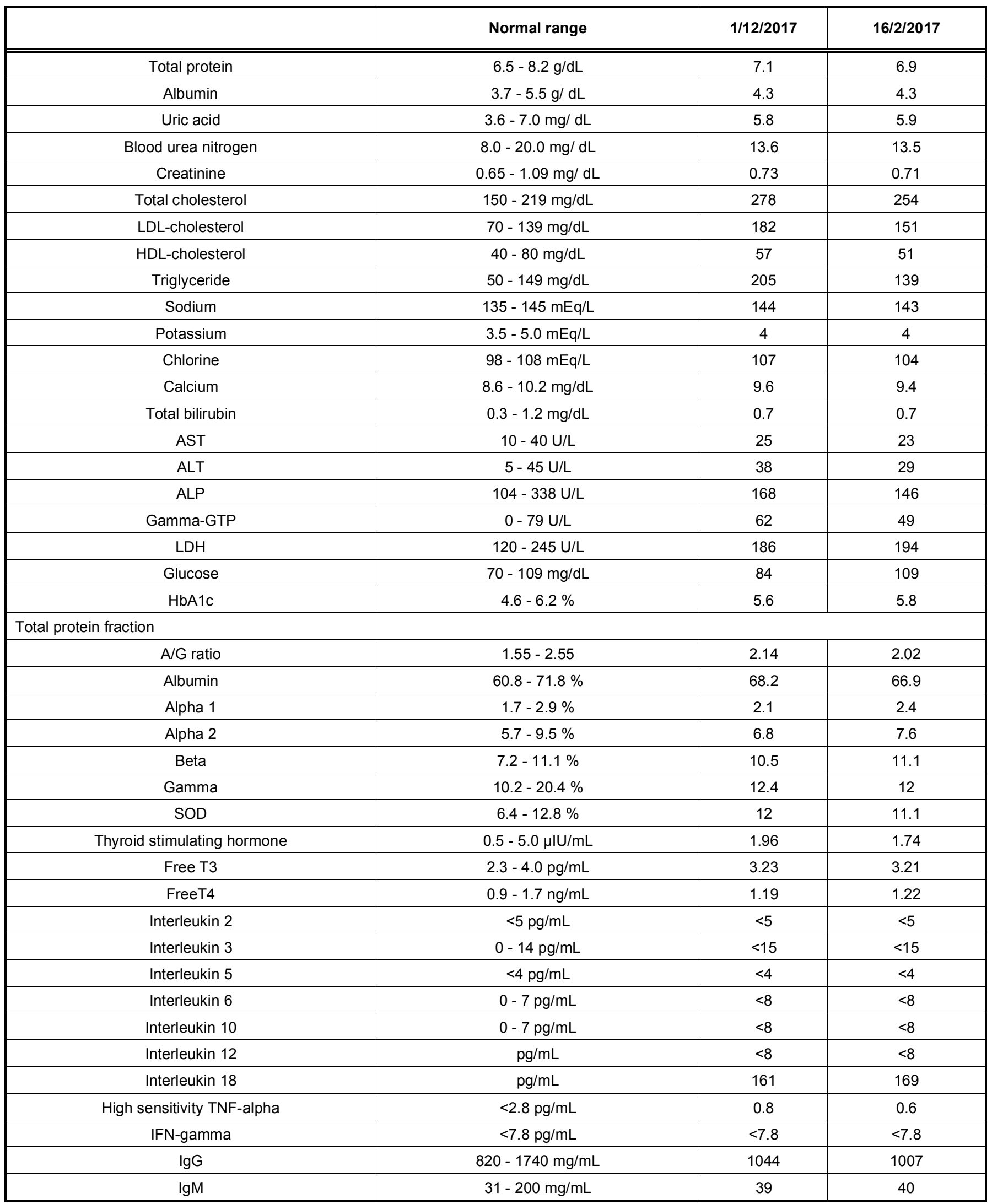

LDH-cholesterol, low density lipoprotein-cholesterol; HDL-cholesterol, high density lipoprotein-cholesterol; AST, aspartate Aminotransferase; ALT, alanine transaminase; APL, alkaline phosphatase; gamma GPT, gamma-glutamyl-transpeptidase; LHD, lactate dehydrogenase; TNF, tumor necrosis factor; IFN, interferon gamma. 
Table 2: Peripheral Blood Test

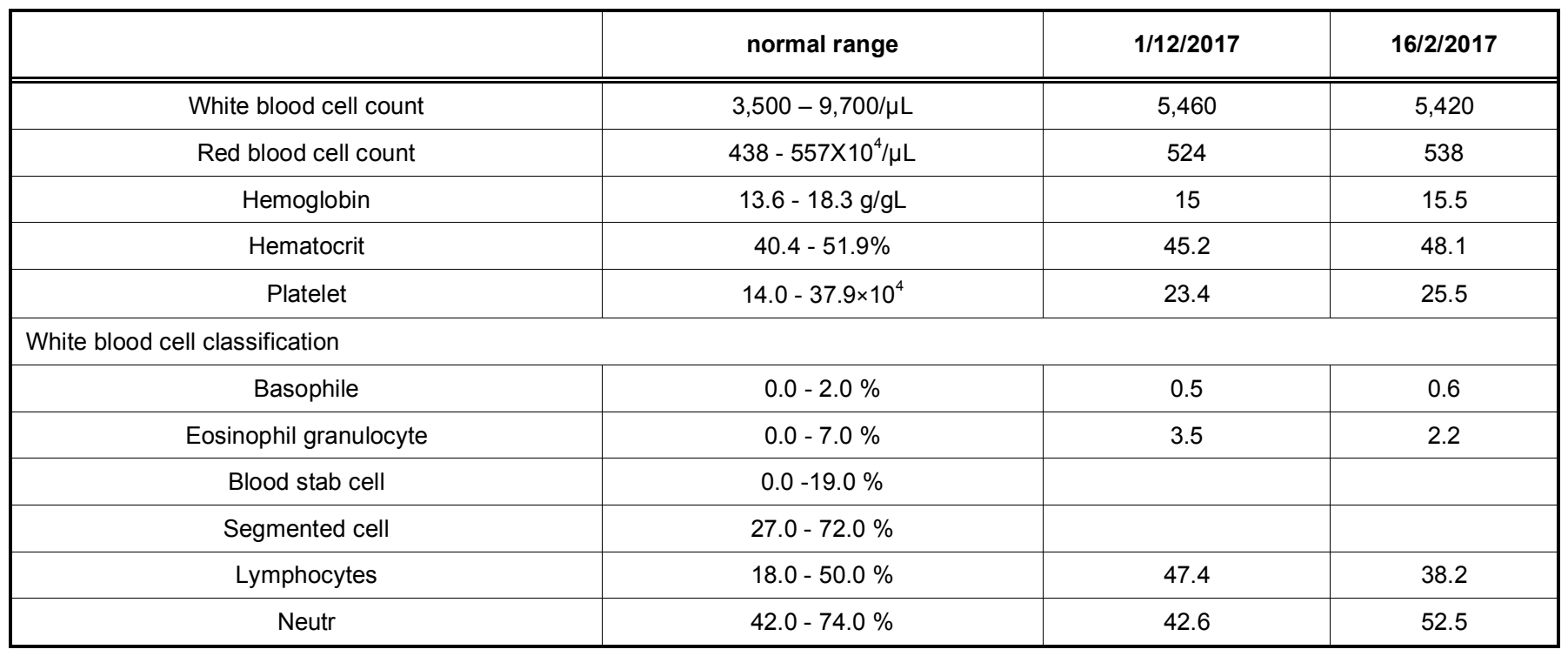

of this experiment was chosen to be limited to the first author, Masao Takatori MD., sixty years old without any past or present disease history. The radioactivity on the surface of the sack was maintained over 400 $\mu S V /$ hour. To investigate the biological influences during the study, biochemical markers were regularly checked in health centers along with thyroid hormone, superoxide dismutase (SOD), intrinsic interleukin, tumor necrosis factor (TNF) -alpha, interferon (IFN) gamma and immunoglobulin at both the initial and end points of the study (Table 1). As a basic data, peripheral blood picture with white blood cell classification was also confirmed at the same periods (Table 2).

\section{RESULTS}

At the initial point of the study, fundamental biochemical data involving liver and renal function showed no abnormality. The lipid-related data showed mild hyperlipidemia based on the low-density lipoprotein (LDL)-cholesterol and triglyceride. The glucose tolerance and thyroid function representing metabolic/endocrine data, SOD as antioxidant marker, and immunological markers, such as interleukin, TNFalpha, IFN-gamma and immunoglobulin were within normal range. There was no abnormality in peripheral blood picture as well. At the endpoint of the study, all biomarkers including lipid-related markers, were found to be within their respective normal ranges. On comparing the initial and end point readings of clinical laboratory investigations, no definite changes or aggravations were observed (Tables 1, 2).

\section{DISCUSSION}

The significance of low-level radiation is still controversial $[6,7]$; and the approach to confirm it has not been established yet. We have previously reported the experimental direct exposure of alpha-ray model by inhaling radon $\left(\mathrm{Rn}^{222}\right)$ gas [9] or drinking $\mathrm{Rn}^{222}$ dissolved water [10]. In the present study, we demonstrated the method of the direct exposure of human body to beta- and gamma-rays by wearing a cotton sack with a piece of samarskite. The method was limited within the range of low-level radiation; this procedure was quite simple and available to control the radioactive exposure levels by the selection of minerals with different radioactivity. Unlike uraninite, samarskiterelated minerals are not legally prohibited in a quantitative management and can easily be obtained. Though the contact area between skin and sack is narrow, wearing a sack with radioactive minerals would be convenient for a subject to maintain stable exposure. It is thus indispensable to establish and define an informed consent for collecting more study participants to evaluate the effect of this method. Our previous reports demonstrated the possibility of biopositive effect using low-level radiation hormesis in various situations as an alternative treatment [8, 9]; however, the accumulation of fundamental data based on the adjusted radioactive exposure conditions were insufficient. The present trial based on a separate radioactive exposure condition suggested that this simple method would be helpful to define the accurate radioactive threshold for human beings. 
Limited in a personal condition, the present study demonstrated that contacting a low-level radioactive mineral for a certain time would not be harmful to human beings, which was supported by the blood test results including various biochemical, metabolic and immunological markers. These results could be the basis for further investigations and evaluations, such as the significance of low-level radiation and the verification of its harmfulness to human beings in an accurate radioactive threshold. The additional data based on different conditions (radiation exposure condition both in radioactive and cumulative levels) is required. Along with these investigations, a wide range of evaluation of biomarkers, including genetic studies will however be called for.

\section{CONCLUSION}

The simplicity of the method adopted in this study may be useful to gather further investigational data that would be reliable for statistical analysis. This data collection is felt necessary to indicate the accurate bioeffectiveness of low radiation and determine the radioactive threshold for human beings as well.

\section{ACKNOWLEDGEMENT}

We specially thank Mr. Tamaki for providing a piece of Samarskite used in this study.

\section{REFERENCES}

[1] Vaiserman A, Koliada A, Zabuga O, Socol Y. Health Impacts of Low-Dose lonizing Radiation: Current Scientific Debates and Regulatory Issues. Dose-response: a publication of
International Hormesis Society 2018; 16(3): 1559325818796331

https://doi.org/10.1177/1559325818796331

[2] Feinendegen LE, Pollycove M. Biologic responses to low doses of ionizing radiation: detriment versus hormesis. 1. Dose responses of cells and tissues. J Nucl Med 2001; 42(7): $17 \mathrm{~N}-27 \mathrm{~N}$.

[3] Pollycove M, Feinendegen LE. Biologic responses to low doses of ionizing radiation: detriment versus hormesis. 2. Dose responses of organisms. J Nucl Med 2001; 42(9): 26N$37 \mathrm{~N}$

[4] Kondo S. Health effects of low level radiation. Madison, WI: Medical Physics 1993; 85-89.

[5] Feinendegen LE, Loken MK, Booz J, Muhlensiepen $H$ Sondhaus CA, Bond VP. Cellular mechanisms of production and repair induced by radiation exposure and their consequences for cell system responses. Stem Cells 1995; 13(suppl 1): 7-20.

[6] Pearce MS, Salotti JA, Little MP, McHugh K, Lee C, Kim KP et al. Radiation exposure from CT scans in childhood and subsequent risk of leukemia and brain tumors: a retrospective cohort study. Lancet 2012; 380: 499-505. https://doi.org/10.1016/S0140-6736(12)60815-0

[7] Doss $M$. Shifting the paradigm in radiation safety. Dose Response 2012; 10: 562-83. https://doi.org/10.2203/dose-response.11-056.Doss

[8] Takatori M, Hattori S, Yagi M. Clinical significance of low dose radiation hormesis. Int $\mathrm{J}$ low Radiation 2010; 7: 511-19. https://doi.org/10.1504/IJLR.2010.037672

[9] Takatori M, Yagi M, Hattori S. Potential solutions in radiation hormesis. J cancer Respdates 2013; 2: 95-98. https://doi.org/10.6000/1929-2279.2013.02.02.2

[10] Takatori M, Takatori $Y$, Yagi M. Clinical significance of lowlevel radiation exposure om mammalian radiobiology investigated by radon $(\mathrm{Rn} 222)$ dissolved water intake in a dog. J Can Res Updates 2016, 7: 134-137.

DOI: http://dx.doi.org/10.30683/1929-2279.2019.08.09

(c) 2019 Takatori and Yagi; Licensee Neoplasia Research.

This is an open access article licensed under the terms of the Creative Commons Attribution Non-Commercial License (http://creativecommons.org/licenses/by-nc/3.0/) which permits unrestricted, non-commercial use, distribution and reproduction in any medium, provided the work is properly cited. 